\title{
Gestão ambiental de resíduos industriais: análise de gestão e reaproveitamento de resíduos da indústria sucroalcooleira
}

\author{
Fábio Friol Guedes de Paiva*, Vitor Peixoto Klienchen de Maria
}

Universidade Estadual Paulista, UNESP. Rua Cyro Bueno, 40. Jardim Morumbi. Presidente Prudente-SP. Brasil. (CEP 19060-560). *E-mail: fabio.vha@hotmail.com.

Resumo. Devido ao aumento da preocupação ambiental no setor empresarial, o modelo de gestão ambiental recebeu maior atenção para as estratégias e as práticas voltadas para o uso racional dos recursos naturais, minimizando os impactos causados pelo processo produtivo no meio ambiente, como também para o bem-estar dos funcionários. Desta maneira, o objetivo consiste na análise bibliográfica de gestão ambiental realizado no Brasil, levantando os impactos ambientais causados pelo setor sucroalcooleiro, os certificados aplicados para este setor, os métodos de monitoramento e compensação dos danos causados e o desenvolvimento tecnológico aplicado aos resíduos industriais. Foi possível concluir que a preocupação ambiental transformou o cenário empresarial atual e, com um plano de gestão ambiental eficaz, agrega uma visão positiva com os clientes, como também incentivos fiscais pelo governo e ampliação da lucratividade.

Palavras-chave: Gestão ambiental; Resíduo industrial; Bagaço da cana-de-açúcar; Desenvolvimento tecnológico.

\begin{abstract}
Environmental management of industrial residues: analysis of management and reuse of waste from the sugar and alcohol industry. Due to the increased environmental concern in the industrial sector, the environmental management model for the greater attention to strategies and practices aimed at the rational use of natural resources, minimizing the impacts caused by the productive process without environment and wellbeing of employees. In this way, the objective is the bibliographic analysis of the environmental management in Brazil, taking the environmental impacts caused by the sugar and alcohol sector, the certificates applied to the sector, the methods of monitoring and compensation of the damages caused and the technological development applied to the industrial waste. It was possible to conclude that environmental concern has transformed the current business scenario, with an environmental management plan, add a positive vision with the clients, as well as tax incentives by government and increased profitability.
\end{abstract}

Recebido:

$31 / 01 / 2018$

Aceito:

$27 / 04 / 2018$

Publicado:

$30 / 04 / 2018$

Acesso aberto

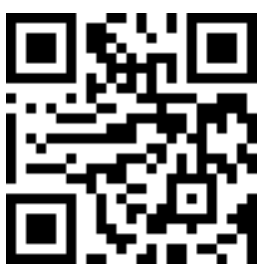

ORCID

(1) 0000-0001-5143-2952 Fábio Friol Guedes de Paiva

D 0000-0001-9104-6490

Vitor Peixoto

Klienchen de Maria 
Keywords: Environmental management; Industrial waste; Sugarcane bagasse; Technological development.

\section{Introdução}

Desde a década de 1990, as empresas compreenderam a necessidade do crescimento econômico combinado com conservação ambiental, observando que a preocupação com os recursos naturais e o seu uso racional forneceria ganhos dentro de um mercado globalizado e competitivo, que propõe incentivos para empresas com gestão ambiental de qualidade, visando também à imagem positiva da empresa diante da comunidade e clientes (Zevieni et al., 2013; Holanda e Ramos, 2016).

o Brasil é atualmente o líder mundial na produção de cana-de-açúcar, com produção em 2017 de 657 milhões de toneladas, correspondendo a $1 / 3$ do total produzido no mundo (CONAB, 2017). A cana-de-açúcar tem diversas aplicações na indústria, sendo principalmente para a produção de açúcar e álcool, combustível, como também biodiesel e na cogeração de energia a partir da queima do bagaço da cana (MAPA, 2016). Atualmente, diversos autores estudam as potencialidades tecnológicas do bagaço da cana, com ênfase no desenvolvimento de materiais sustentáveis e reaproveitamento do excesso de resíduo do processo produtivo (Naguib et al., 2015; Putra et al., 2013).

Diante do crescente desenvolvimento das indústrias sucroalcooleiras e as diversas poluições causadas, as empresas passaram a buscar profissionais que identificassem alternativas para controle e avaliação de impacto ambiental. Diante deste fato, surge a ISO 14000, desenvolvida em Genebra por uma instituição não governamental que estipula um conjunto de normas ambientais, estabelecendo critérios e sistemas para a administração ambiental em uma organização (Monteiro e Ferreira, 2009).
Assim, o objetivo desta pesquisa foi identificar os impactos positivos e negativos da indústria sucroalcooleira, tanto socioeconômicos quanto do processo produtivo, como também 0 destino dos resíduos industriais, identificando soluções de gestão ambiental implantadas por empresas sucroalcooleiras no Brasil.

\section{O setor sucroalcooleiro no Brasil}

Introduzido no período colonial, o cultivo da cana-de-açúcar integra uma das principais culturas da economia brasileira. Segundo Ferreira (2013), a cultura do cultivo da cana-de-açúcar colocou o Brasil não somente como maior produtor do mundo, mas também o primeiro país a produzir o açúcar e o etanol.

De acordo com o CONAB (2015), o setor possui 8,9 milhões de hectares plantados com a cana-de-açúcar, sendo composta por 435 usinas e destilarias. 0 desenvolvimento deste setor movimentou cerca de 60 bilhões de reais, representando $1,6 \%$ do PIB. 0 setor gerou 4,5 milhões de empregos diretos e indiretos, abrangendo 72 mil agricultores. Além disso, arrecadou 15 bilhões em impostos e taxas. Diante desses índices, fica evidente a importância deste setor na economia brasileira.

O Brasil é reconhecido mundialmente pela matriz energética renovável. Hoje, 41,2\% da energia consumida no Brasil é de fonte renovável, sendo a média mundial entre $2 \%$ e $22 \%$. 0 que é pouco divulgado no país é o grande potencial energético envolvendo a canade-açúcar, onde é a matéria-prima para a produção do etanol e da bioeletricidade, correspondendo por $16,9 \%$ da energia produzida no Brasil, ficando atrás apenas do petróleo e derivados (MME, 2016). 


\section{Gestão ambiental nas organizações e suas potencialidades}

A definição de gestão ambiental envolve uma série de medidas e procedimento que visão reduzir e controlar os impactos introduzidos por um empreendimento sobre o meio ambiente (Rodrigues, 2014).

A discussão global envolvendo a relação entre o homem e o meio ambiente surge a partir de 1962, ano em que a bióloga Rachel Carson publica seu livro Silent Spring (Primavera Silenciosa) (Carson, 2000). Desde então, várias convenções e acordos foram realizados entre as nações. Dentre eles, os principais foram a Conferência de Estocolmo, o Informe Brundtland, a Eco92, Rio+5, Protocolo de Kyoto, COP15, e, dentre as mais recentes, Rio+20. 0 intuito destas convenções e acordos foi de reunir chefes de Estado e buscar alternativas para reduzir o impacto ambiental, onde havia a priorização do progresso econômico e, assim, buscar alternativas para o desenvolvimento sustentável (Monteiro e Ferreira, 2009).

$$
\text { Alperstedt et al. (2010) }
$$

consideram que, dentre os fatores que são determinantes para aderir às práticas ambientais de maior relevância é, em suma, a pressão da sociedade. Com isto, é somado a importância das ações regulamentadoras governamentais, a adequação normativa e a concorrência.

Barbieri (2004) defende três

tipos de abordagens ambientais na empresa. 0 primeiro voltado para o controle da poluição, onde deve ser cumprido a legislação ambiental e atendido aos problemas levantados pela comunidade. Este tipo envolve uma postura reativa e vinculada, pois é exclusivamente da área produtiva. Por outro lado, a postura da empresa pelas questões ambientais pode ser preventiva, isto é, utilização efetiva dos insumos pela organização. No último estágio, a questão ambiental resulta em um fator estratégico da empresa, abrangendo não só a área manufatureira, mas passa a expandir para todas as áreas da organização.

\section{Certificações ambientais e o setor sucroalcooleiro}

Com o surgimento da preocupação ambiental, surge uma discussão global de como atestar que determinado produto ou setor esteja seguindo as determinações/legislações para alcançar o desenvolvimento sustentável e limpo. Para determinar se está seguindo as determinações, a certificação ambiental é uma das maneiras encontradas para tentar responder essa questão (Ferracioli, 2013). Segundo Macedo (2002), as certificações têm função primária de punir os poluidores e premiar os produtores que assumem ações sustentáveis, também sinalizando para o consumidor quem está de acordo com os ideais desejados.

Desta forma, os primeiros selos que o setor sucroalcooleiro buscou foram os ISOs (International Organization for Standardization), envolvendo a ISO 9001:2008, de gestão de qualidade, a ISO 14001:2004, de gestão ambiental, e a OHSAS 18001:2007, de gestão de segurança e saúde ocupacional.

Atualmente, a grande maioria dos produtores canavieiros do Estado de São Paulo aderem ao Protocolo Agroambiental, que garante ao bioetanol produzido o selo de conformidade agroambiental (São Paulo, 2002, SGS, 2012).

Este protocolo, firmado em 2007, adianta os prazos estabelecidos na Lei $\mathrm{n}^{\mathrm{o}}$ $11.241 / 2002$ para um dos principais problemas gerados pelo plantio de canade-açúcar, as queimadas. A lei adianta o prazo para o fim das queimadas em São Paulo de 2031 para 2017 (Tabelas 1 e 2), e o Protocolo Agroambiental ainda complementa ações ambientais não previstas nas leis, de caráter voluntário. As medidas adotadas são de racionalidade do consumo de água, preservação de reservas e matas ciliares, redução da emissão de poluentes, entre outros. 
Tabela 1. Cronograma de eliminação da queima da palha da cana-de-açúcar nas colheitas de acordo com a Lei no 11.241/2002 para áreas mecanizáveis (São Paulo, 2007; Ferracioli, 2013).

\begin{tabular}{cc}
\hline Áreas mecanizáveis (com declividade do terreno igual ou inferior a 12\%) \\
\hline $1^{\circ}$ ano $(2002)$ & Eliminação de $20 \%$ da queima \\
$5^{\circ}$ ano $(2006)$ & Eliminação de $30 \%$ da queima \\
$10^{\circ}$ ano $(2011)$ & Eliminação de $50 \%$ da queima \\
$15^{\circ}$ ano $(2016)$ & Eliminação de $80 \%$ da queima \\
$20^{\circ}$ ano $(2021)$ & Eliminação de $100 \%$ da queima \\
\hline Áreas não mecanizáveis (com declividade do terreno superior a 12\%) \\
\hline $10^{\circ}$ ano $(2011)$ & Eliminação de $10 \%$ da queima \\
$15^{\circ}$ ano $(2016)$ & Eliminação de $20 \%$ da queima \\
$20^{\circ}$ ano $(2021)$ & Eliminação de $30 \%$ da queima \\
$30^{\circ}$ ano ano $(2026)$ & Eliminação de $50 \%$ da queima \\
\hline
\end{tabular}

Tabela 2. Cronograma de eliminação da queima da palha da cana-de-açúcar nas colheitas de acordo com o Protocolo Agroambiental de 2007 (São Paulo, 2007; Ferracioli, 2013).

\begin{tabular}{cc}
\hline Áreas mecanizáveis (com declividade do terreno igual ou inferior a 12\%) \\
\hline 2010 & Eliminação de $70 \%$ da queima \\
2014 & Eliminação de $100 \%$ da queima \\
Áreas não mecanizáveis (com declividade do terreno superior a 12\%) \\
2010 & Eliminação de $30 \%$ da queima \\
2017 & Eliminação de $100 \%$ da queima
\end{tabular}

Ainda há dificuldade em conformizar um selo universal que atenda às exigências conforme os ideais sustentáveis. O Bonsucro possui somente 12 dos certificados aceitos pela Diretiva Europeia (dentre 426 certificados), voltados para biocombustível. Por meio desse certificado que são realizadas ações para as emissões de GEEs (Gases de efeito estufa), consumo de energia, questões trabalhistas e o uso racional da água e agrotóxicos são monitorados (Bonsucro, 2013; Ferracioli, 2013).

De modo geral, a certificação resulta na definição e padronização quanto aos produtos, serviços, sistemas ou pessoas, para que seja encontrada em normas preestabelecidas (Hatanaka, 2010). Sendo assim, as certificações ambientais têm sua classificação de acordo ao tipo, sendo aos produtos e serviços, sistemas de gestão e de pessoas; ao caráter de adesão, podendo ser voluntário ou compulsório e; de acordo com a natureza na qual será realizada a auditoria (Oliveira, 2013).

\section{Práticas e impactos ambientais}

Atualmente, a prática de conscientização ambiental nas empresas demonstrou benefícios importantes. Sanches (2000) defende que:

A proteção ambiental passa a fazer parte de seus objetivos de negócios e o meio ambiente não é mais encarado como um adicional de custo, mas como uma possibilidade de lucros, em um quadro de ameaças e oportunidades para a empresa (Sanches, 2000: 78).

Alinhado a esta visão, é importante ressaltar que determinadas práticas de produção limpa venham a reduzir os custos, como também possibilitar vantagens ambientais $\mathrm{e}$ competitivas. A lógica consiste na prática conhecida como 5Rs: reduzir, reutilizar, reciclar, reproduzir e recuperar. São requisitos básicos quando voltados para a produção de produtos e serviços de alta qualidade, com pouco ou zero resíduos (Rahman et al., 2009). 
Rahman et al. (2009) conduziram pesquisas com base nestes conceitos de produção limpa em pequenas e médias empresas na Indonésia. Foi analisado pelos autores que uma das empresas alcançou redução de $70 \%$ nos custos de produção, devido à redução de retrabalho, resíduos e economia de energia. Demonstrando a melhoria ambiental e a contribuição competitiva que a produção limpa proporciona.

No que envolve os impactos ambientais da produção sucroalcooleiro, Santo e Almeida (2007) consideram os seguintes aspectos: (a) impactos causados pela queima da palha da cana, (b) impacto na qualidade da água e consumo para irrigação, (c) expansão da fronteira agrícola e desmatamento, (d) uso de defensivos agrícolas envolvendo a contaminação do solo e (e) o desgaste do solo pelas queimadas.

\section{Usina Uberaba}

A Gaia Consultoria e Gestão Ambiental fez uma análise do plano de gestão ambiental da Usina Uberaba, em Uberaba (MG), em 2016. Foi traçado planos para atender às necessidades estabelecidas pelo Certificação Better Sugarcane Initiative (Bonsucro) e, como finalidade, apresentar ações, programas, medidas de controle ambiental e planos para mitigação dos impactos ambientais (Barreto, 2016).

A empresa tem como objetivos a produção de álcool etílico pelo processamento da cana-de-açúcar e energia, pela queima do bagaço da canade-açúcar em uma usina termoelétrica. Com isso, a Gaia consultoria avaliou os impactos ambientais considerando $\mathrm{o}$ conceito de abordagem dirigida, direcionando os dados levantados e efetivamente utilizados na análise com suas relações de causa e efeito. Foi identificado 23 impactos, desde o plantio à produção de álcool e geração de energia. Destes impactos, foi verificado que 17 são impactos negativos e 06 impactos positivos, conforme a Tabela 3 (Barreto, 2016).

Nesta abordagem pôde ser observado que todos os impactos negativos são de baixa ou média relevância, derivado de gestões já desenvolvidas pela empresa para minimização desses impactos. Todo impacto positivo é considerado pela Gaia consultoria como de alta relevância e muito significativo, devido à grande importância econômica para a população do município de Uberaba e região, tal como para o meio ambiente.

\section{Medidas de monitoramento, mitigação e compensação \\ Após o levantamento dos} impactos ambientais e aplicação tecnológica para reduzir ou sanar os problemas encontrados na Usina Uberaba, foi realizado medidas de monitoramento, mitigação e compensação dos danos ambientais causados, a empresa também adotou medidas que garantem a plena proteção com o pessoal próprio e terceirizado, desenvolvendo ações típicas de medicina preventiva, como a vacinação e ações de conscientização sobre a saúde de forma geral (Barreto, 2016). 
Tabela 3. Avaliação das principais questões ambientais (Barreto, 2016).

\begin{tabular}{|c|c|c|c|c|}
\hline Principais Questões Ambientais & $\begin{array}{c}\text { Naturez } \\
\text { a }\end{array}$ & Significância & $\begin{array}{l}\text { Ação de } \\
\text { Gestão }\end{array}$ & Relevância \\
\hline $\begin{array}{l}\text { Supressão de remanescentes de } \\
\text { vegetação nativa }\end{array}$ & Negativo & $\begin{array}{c}\text { Muito } \\
\text { significativo }\end{array}$ & $\begin{array}{l}\text { Controle e } \\
\text { mitigação }\end{array}$ & $\begin{array}{l}\text { Média } \\
\text { relevância }\end{array}$ \\
\hline $\begin{array}{l}\text { Supressão de indivíduos arbóreos } \\
\text { isolados }\end{array}$ & Negativo & Significativo & Cont. e mit. & Baixa rel. \\
\hline Alteração da paisagem local & Negativo & Pouco sign. & Cont. e mit. & Baixa rel. \\
\hline Afugentamento da fauna local & Negativo & Pouco sign. & $\begin{array}{c}\text { Cont. e } \\
\text { monitorament } \\
\text { o }\end{array}$ & Baixa rel. \\
\hline Atropel amento da fauna local & Negativo & Pouco sign. & Cont. e mon. & Irrelevante \\
\hline Serviços ecossistêmicos & Positivo & Muito sign. & Potencialização & Alta rel. \\
\hline $\begin{array}{l}\text { Ação de processos erosivos no solo } \\
\text { e assoreamento de cursos d'água }\end{array}$ & Negativo & Significativo & Cont. e mit. & Baixa rel. \\
\hline Compactação do solo & Negativo & Significativo & Mitigação & Irrelevante \\
\hline Redução da disponibilidade hídrica & Negativo & Pouco sign. & Mit. e mon. & Baixa rel. \\
\hline $\begin{array}{l}\text { Emissão de particulados de fontes } \\
\text { pontuais }\end{array}$ & Negativo & Pouco sign. & Mit. e mon. & Irrelevante \\
\hline $\begin{array}{l}\text { Emissão de particulados de fontes } \\
\text { difusas }\end{array}$ & Negativo & Pouco sign. & Cont. e mon. & Irrelevante \\
\hline Mudança climática & Positivo & Muito sign. & Potencialização & Alta rel. \\
\hline $\begin{array}{l}\text { Risco de contaminação de solos e } \\
\text { coleções hídricas }\end{array}$ & Negativo & Significativo & Controle & Baixa rel. \\
\hline Fertirrigação & Negativo & Significativo & Cont. e mon. & Baixa rel. \\
\hline Geração de resíduos sólidos & Negativo & Significativo & Cont. e mon. & Baixa rel. \\
\hline Geração de pressão sonora & Negativo & Pouco sign. & Cont. e mon. & Irrelevante \\
\hline $\begin{array}{l}\text { Aumento dos custos de habitação, } \\
\text { alimentação e serviços }\end{array}$ & Negativo & Pouco sign. & Mitigação & Irrelevante \\
\hline $\begin{array}{l}\text { Ampliação dos riscos de acidentes } \\
\text { com automóveis e transporte de } \\
\text { funcionários }\end{array}$ & Negativo & Muito sign. & Mitigação & Média rel. \\
\hline $\begin{array}{l}\text { Geração de elevada expectativa de } \\
\text { empregos }\end{array}$ & Negativo & Significativo & Controle & Baixa rel. \\
\hline Geração de emprego e renda & Positivo & Muito sign. & Potencialização & Alta rel. \\
\hline Fomento à economia da região & Po & Muito sign. & Potencialização & Alta rel. \\
\hline $\begin{array}{l}\text { Aumento na arrecadação de } \\
\text { impostos }\end{array}$ & Positivo & Muito sign. & Potencialização & Alta rel. \\
\hline Geração de benefícios sociais & Positivo & Muito sign. & Potencialização & Alta rel. \\
\hline
\end{tabular}

A seguir é apresentado ações desenvolvidas pela empresa para minimização dos impactos ambientais relacionados à atividade sucroalcooleira, conforme a Tabela 4. 
Tabela 4. Medidas de monitoramento, mitigação e compensação (Barreto, 2016).

\begin{tabular}{|c|c|c|}
\hline Item & Duração & Periodicidade \\
\hline $\begin{array}{l}\text { Ação de conscientização junto aos proprietários rurais da } \\
\text { região, dando suporte técnico para as questões ambientais } \\
\text { (regularização, supressão de vegetação, etc). }\end{array}$ & Permanente & Sob demanda \\
\hline $\begin{array}{l}\text { Plano de Aplicação de Resíduos Industriais no solo } \\
\text { (fertilizante orgânico). }\end{array}$ & Permanente & Anual \\
\hline $\begin{array}{l}\text { Plano de Aplicação de Vinhaça, conforme norma COPAM no } \\
164 / 2011 .\end{array}$ & Permanente & Anual \\
\hline Programa de monitoramento da Fauna de Vertebrados. & 2 anos & Semestral \\
\hline ntação e execução da coleta seletiva no pátio industrial. & Permanente & Constante \\
\hline Plano de Educação Ambiental, norma COPAM no 110/2007. & Permanente & Anual \\
\hline $\begin{array}{l}\text { Plano de Comunicação Social, conforme proposto no } \\
\text { EIA/RIMA. }\end{array}$ & Permanente & Anual \\
\hline Monitoramento das emissões atmosféricas de chaminés. & Permanente & Trimestral \\
\hline Acõos de proteção das APP e reserva legal. & Permanente & Sob demanda \\
\hline Monitoramento dos efluentes líquidos sanitários. & Permanente & Trimestral \\
\hline $\begin{array}{l}\text { Programa de monitoramento da qualidade das águas } \\
\text { superficiais. }\end{array}$ & Permanente & Trimestral \\
\hline Inventário de Resíduos Sólidos Industriais. & Permanente & Anual \\
\hline $\begin{array}{l}\text { Monitoramento da vazão de captação dos poços tubulares e } \\
\text { da captação superficial. }\end{array}$ & Permanente & Semanal \\
\hline Programa de controle e sinalização do tráfego. & 02 anos & Anual \\
\hline da caldeira. & Permanente & Imediato \\
\hline nálise de área fertirrigada. & Permanente & Anual \\
\hline Aplicação de defensivos agrícolas apenas com profissional. & Permanente & Constante \\
\hline $\begin{array}{l}\text { Impermeabilização de reservatório de vinhaça e água } \\
\text { residuária. }\end{array}$ & Permanente & Imediato \\
\hline $\begin{array}{l}\text { Programa interno de autofiscalização quanto a emissão de } \\
\text { fumaça preta, conforme portaria IBAMA no } 85 / 1996 \text {. }\end{array}$ & Permanente & Anual \\
\hline Realização de rotação nas áreas de reforma de canavial. & Permanente & A cada ciclo \\
\hline $\begin{array}{l}\text { Manutenção de vias de circulação com a aspersão de água } \\
\text { para evitar a dispersão de poeira. }\end{array}$ & Permanente & $\begin{array}{l}\text { Anual, de maio a } \\
\text { setembro }\end{array}$ \\
\hline Programa de Gerenciamento de Riscos - PGR. & Permanente & Anual \\
\hline Plano de Prevenção de Riscos Ambientais - PPRA. & Permanente & Anual \\
\hline $\begin{array}{l}\text { Programa de monitoramento da ocorrência da mosca-dos- } \\
\text { estábulos (Stomoxys calcitrans) nas áreas fertirrigadas. }\end{array}$ & Permanente & Semestral \\
\hline Monitoramento dos efluentes líquidos. & Permanente & Semestral \\
\hline Programa de Gerenciamento de Resíduos Sólidos - PGRS. & Permanente & Constante \\
\hline Instalação de depósito de embalagens de agroquímicos. & Permanente & Imediato \\
\hline Programa de Redução de utilização de agrotóxicos. & Permanente & Constante \\
\hline $\begin{array}{l}\text { Implantação de sistemas de tratamento, recirculação, } \\
\text { resfriamento e decantadores para as águas industriais, }\end{array}$ & Permanente & Imediato \\
\hline
\end{tabular}

\section{Resíduos e subprodutos sucroalcooleiros}

A indústria sucroalcooleira busca alternativas para que seus resíduos se transformem em subprodutos, no qual agregará valor comercial para diversas cadeias produtivas. Vale a pena ressaltar que os resíduos antes considerados como problemas ambientais e de estocagem, hoje passaram a agregaram grande fonte de renda para as empresas (Chuba et al., 2010).

Dentre os resíduos produzidos, há muitos que se encontradram em uma categoria de reuso para adubação e fertirrigação da colheita. Os exemplos para fertirrigação são: efluentes de lavagem da cana, efluentes de descarga 
de caldeiras, melaço, vinhaça e efluente da lavagem das dornas. Para adubação, Rodrigues (2014) ainda cita o bagaço da cana-de-açúcar, cinzas da queima do bagaço, iodo proveniente da descarga das caldeiras, torta de filtro e sólidos decantados.

É importante citar a versatilidade de aplicações do bagaço da cana-deaçúcar. Segunda a União da Indústria de Cana-de-Açúcar (UNICA, 2012), cada tonelada da cana gera $280 \mathrm{~kg}$ de bagaço e $234 \mathrm{~kg}$ de palha e pontas. Esses materiais são aproveitados para a geração de bioenergia, com a tecnologia atual, não gera poluição para o meio ambiente e chega a produzir $500 \mathrm{kWh}$ por tonelada do resíduo. Estudos recentes relatam a potencialidade tecnológica do bagaço da cana, com propriedades mecânicas, térmicas e acústicas quando incorporado há polímeros, como também a importante viabilidade econômica do resíduo e por ser uma alternativa renovável em relação aos materiais sintéticos (Naguib, 2015; Putra, 2013).

0 processo de biogeração de energia resulta em um material conhecido por cinza do bagaço da canade-açúcar. Este resíduo possui alta concentração de sílica, composto importante para aumentar a resistência de materiais cerâmico, sendo o cimento Portland um dos materiais que tem a sílica como ingrediente da formulação. Portanto é um material de baixo custo, abundante e que é descartado pela indústria (Santos, 2014).

Com isso, pôde ser observado a importância da cana-de-açúcar para diversos meios produtivos, com potencial econômico e tecnológico para substituir materiais não renováveis e de alto custo.

\section{Conclusão}

Considerando a nova realidade empresarial, foi possível compreender a importância da gestão ambiental de qualidade, levantando os principais aspectos para apurar as práticas ambientais, considerando as estratégias e o valor de inserir os resíduos, antes descartados, como subprodutos para a continuidade do cultivo da cana-deaçúcar e manutenção do solo.

O setor foi alvo de muitas críticas recentes devido aos impactos ambientais, mas com o aumento da regulamentação e a procura de melhorar a visão da empresa com a população, foi possível que muitas das iniciativas fossem tomadas pelas próprias empresas, chegando a reduzir prazos pré-estipulados pela legislação nacional, resultado do investindo em gestão ambiental para a otimização dos processos produtivos e obtenção das certificações ambientais.

É válido ressaltar que ao aderir às iniciativas ambientais, 0 setor sucroalcooleiro passou a obter lucratividade em vários setores, o que antes era visto como problema transformou-se em oportunidade, aplicando resíduos na fertirrigação, adubação, como biomassa e, principalmente, estudar o resíduo do bagaço e da cinza da cana-de-açúcar para substituir materiais não renováveis, de alto custo e que prejudicam o meio ambiente quando chegam no final de sua vida útil.

\section{Declaração de conflito de interesses}

Os autores declaram não haver conflito de interesses.

\section{Referências}

Alperstedt, G. D.; Quintella, R. H.; Souza, L. R. Estratégias de gestão ambiental e seus fatores determinantes: uma análise institucional. Revista de Administração de Empresas, v. 50, p. 170-186, 2010. https://doi.org/10.1590/S0034-759020100 00200004

Barbieri, J.C. Gestão ambiental empresarial. São Paulo: Saraiva, 2004.

Barreto, G. F.; Almeida, B. A.; Oliveira, L. B. Plano de Gestão de Impacto Ambiental 
(EIMP). Uberaba: Mater Gaia Consultoria e Planejamento Ambiental, 2016. (revisão-02).

Bonsucro. Bonsucro at a glance. Londres: Bonsucro, 2013. (v. 1.0). Disponível em: $<$ http://bonsucro.com/assets/bonsucro_at_a _glance.pdf>. Acesso em: 17 jan. 2017.

Carson, R. Primavera silcenciosa. São Paulo: Gaia, 2000.

Chuba, C. A. M.; Argandona, E. J. S.; Homem, G. R.; Tommaselli, M. A. G. Modelo de viabilização da produção do consórcio: macaúba (Acrocomia aculeata) e cana-deaçúcar (Saccharum officinarum). Anais do XXX Encontro Nacional de Engenharia de Produção, ENEGEP, São Carlos, 2010.

CONAB - Companhia Nacional de Abastecimento. Acompanhamento da safra brasileira, Brasília, 2015. v. 2, n. 3., p. 8. Disponível em: <http://www.conab.gov.br/ OlalaCMS/uploads/arquivos/15_12_17_09_0 3_29_boletim_cana_portugues_-_3o_lev_-_1516.pdf>. Acesso em: 07 dez. 2016.

CONAB - Companhia Nacional de Abastecimento. Acompanhamento da safra brasileira de cana-de-açúcar - Safra 2017/18. v. 4, n. 2, 2017. Disponível em: <http://www.conab.gov.br/OlalaCMS/uploa ds/arquivos/17_08_24_08_59_54_boletim_ca na_portugues_-_2o_lev_-_17-18.pdf>. Acesso em: 10 dez. 2017.

Ferracioli, K.; Jacomini, R. L.; Marques, P. V. Certificados ambientais e o setor sucroalcooleiro paulista: estudo de caso. Revista Política Agrícola, v. 12, n. 3, p. 96109, 2013. Disponível em: <https://seer.sede.embrapa.br/index.php/R PA/article/download/775/732>. Acesso em: 10 set. 2017.

Ferreira, M. C. Gestão ambiental: um estudo de empresas do setor sucroalcooleiro em Goiás. RPCA, v. 7, p. 59-80, 2013. https://doi.org/10.12712/rpca.v7i3.264

Hatanaka, M. Certification, partnership, and morality in a organic shrimp network: rethinking transnational alternative agrifood networks. World Development, v. 38, p.706716, 2010. https://doi.org/10.1016/ j.worlddev.2009.11.001

Holanda, L. R.; Ramos, F. S. Reuse of waste sugarcane agribusiness and green power generation. Journal of Clean Energy Technologies, v. 4, n. 5, p. 341-345, 2016. Disponível em: <http://www.jocet.org/ vol4/309-R0020.pdf>. Acesso em: 10 set. 2017.
Macedo, Z. L. Os limites da economia na gestão ambiental. Margem, n. 15, p. 203-222, 2002. Disponível em: <http://www.pucsp. $\mathrm{br} / \mathrm{margem} / \mathrm{pdf} / \mathrm{m} 15 \mathrm{zlm} . \mathrm{pdf}>$. Acesso em: 10 set. 2017.

MAPA - Ministério da Agricultura e do Abastecimento. Produção brasileira de canade-açúcar. DCAA/SPAE/MAPA. 2016. Disponível em: <http://www.agricultura. gov.br/arq_editor/Pasta\%20de\%20Agosto\% 20-\%202016.pdf>. Acesso em: 10 set. 2016.

MME - Ministério de Minas e Energia. Balanço Energético Nacional. Rio de Janeiro: MME, 2016. Disponível em: <https://ben.epe.gov.br/downloads/Síntese \%20do\%20Relatório\%20Final_2016_Web.pd f>. Acesso em: 07 dez. 2016.

Monteiro, T.P.P.; Ferreira, P. A. Gestão e meio ambiente: um estudo de caso em uma usina sucroalcooleira. Sociedade Brasileira de Economia, Administração e Sociologia Rural (SOBER). Campo Grande, 2009.

Naguib, H. M.; Kandil, U. F.; Hashem, A. I.; Boghdadi, Y. M. Effect of fiber loading on the mechanical and physical properties of "green" bagasse - polyester composite. Journal of Radiation Research and Applied Sciences, v. 8, p. 544-548, 2015. https://doi.org/10.1016/j.jrras.2015.06.004

Oliveira, E. C.; Pereira, R. S.; Gaspar, M.A. Implementação de certificação ambiental better sugarcane initiative - Bonsucro: estudo de caso no setor sucroenergético. Revista Ibero-Americana de Ciências Ambientais, v. 4 , n. 2, p. $24-45$, 2013. https://doi.org/ 10.6008/ESS2179-6858.2013.002.0002

Putra, A.; Abdullah, Y.; Efendy, H. ; Farid, W. M.; Ayob, M. R.; Py, M. S. Utilizing sugarcane wasted fibers as a sustainable acoustic absorver. Journal Procedia Engineering, v. 53, p. 632-638, 2013. https://doi.org/10.1016/j.proeng.2013.02.0 81

Rahman, M. N. A.; Hernadewita; Deros, B. M.; Ismail, A. R. Cleaner production implementation towards environmental quality improvement. European Journal of Scientific Research, v. 30, p. 187-194, 2009.

Rodrigues, A. M.; Rebelato, M. G.; Paixão, R. B. S.; Zeviani, C. H. Gestão Ambiental no Setor Sucroenergético: uma análise comparativa. Revista Produção Online, v. 14, n. 4, p. 1481-1510, 2014. http://dx.doi.org/ 10.14488/1676-1901.v14i4.1717 
Sanches, C.S. Gestão Ambiental proativa. Revista de Administração de Empresas, v. 40 , n. 1, p. 76-87, 2000. https://doi.org/ 10.1590/S0034-75902000000100009

Santo, Z. N. E.; Almeida, L. T. Etanol: impactos socioambientais de uma commodity em ascensão. Anais do VII Encontro da Sociedade Brasileira de Economia Ecológica, Fortaleza, 2007.

Santos, R. J.; Agostini, D. L. S.; Cabrera, F. C.; Reis, E. A. P.; Ruiz, M. R.; Budemberg, E. R.; Teixeira, S. R.; Job, A. E. Sugarcane bagasse ash: new filler to natural rubber composite. Polímeros, v. 24, n. 6, p. 646-653, 2014. http://dx.doi.org/10.1590/0104-1428.1547

São Paulo. Lei no 11.241, de 19 de setembro de 2002. Dispõe sobre a eliminação gradativa da queima da palha da cana-de-açúcar e dá providências correlatas. Disponível em: <http://www.al.sp.gov.br/ repositorio/legislacao/lei/2002/lei-1124119.09.2002.html>. Acesso em: 12 dez. 2017.

São Paulo. Protocolo de intenções que celebram entre si, o Estado de São Paulo, por intermédio das Secretarias de Estado do Meio Ambiente, de Agricultura e
Abastecimento e a União da indústria de cana-de-açúcar para a adoção de ações destinadas a consolidar o desenvolvimento sustentável da indústria da cana-de-açúcar no Estado de São Paulo. 2007. Disponível em: <http://arquivos.ambiente.sp.gov.br/etanolv erde/2016/12/Protocolo_UNICA_2015.pdf>. Acesso em: 23 dez. 2016.

SGS-Societe Generale de Surveillance. Serviços por tipo: certificação. 2012. Disponível em: <http://www.sgsgroup. com.br/pt-BR/Service-by-Type-

Path/Certification.aspx>. Acesso em: $12 \mathrm{dez}$. 2016.

UNICA - União da Indústria de Cana-deAçúcar. Conquistas do setor sucroenergético na matriz energética brasileira. 2012. Disponível em: <http://www.unica.com.br/ faq/>. Acesso em: 10 nov. 2016.

Zeviani, C. H.; Rodrigues, A. M.; Rebelato, M. G. Elaboração de um roteiro de pesquisa para avaliação do desempenho ambiental em empresas industriais. Anais do XXXIII Encontro Nacional de Engenharia de Produção (UENEGEP), Salvador, ABREPRO, 2013. 